\title{
Rose myrtle (Rhodomyrtus tomentosa) extract and its component, piceatannol, enhance the activity of DNA polymerase and suppress the inflammatory response elicited by UVB-induced DNA damage in skin cells
}

\author{
SAWAKO SHIRATAKE ${ }^{1}$, TATSUO NAKAHARA ${ }^{1}$, HIROYASU IWAHASHI ${ }^{1}$, \\ TAKEFUMI ONODERA ${ }^{2}$ and YOSHIYUKI MIZUSHINA ${ }^{2,3}$ \\ ${ }^{1}$ Research Center, Maruzen Pharmaceuticals Co., Ltd., Onomichi, Hiroshima 722-0062; \\ ${ }^{2}$ Cooperative Research Center of Life Sciences, Kobe Gakuin University, Kobe, Hyogo 650-8586; \\ ${ }^{3}$ Laboratory of Functional Food Science, Graduate School of Agriculture, \\ Shinshu University, Kamiina-gun, Nagano 399-4598, Japan
}

Received September 26, 2014; Accepted July 7, 2015

DOI: $10.3892 / \mathrm{mmr} .2015 .4156$

\begin{abstract}
A number of naturally occurring agents are hypothesized to protect against ultraviolet (UV)-induced skin damage. The present study screened $>50$ plant extracts for inhibitors of UVB-induced cytotoxicity, using cultured normal human epidermal keratinocytes (NHEK), and identified that the fruit of rose myrtle (Rhodomyrtus tomentosa) was the most marked inhibitor of cell death. The protective effect of rose myrtle extract and the two key components, piceatannol and piceatannol-4'-O- $\beta$-D-glucopyranoside, on UVB-induced damage and inflammation in cultured NHEK was investigated. The $80 \%$ ethanol extract from rose myrtle fruit with piceatannol exhibited protection of UVB-induced cytotoxicity in NHEK; however, piceatannol-4'-O- $\beta$-Dglucopyranoside exhibited no protection, as determined by a 3-(4,5-dimethylthiazol-2-yl)-2,5-diphenyltetrazolium
\end{abstract}

Correspondence to: Dr Yoshiyuki Mizushina, Laboratory of Functional Food Science, Graduate School of Agriculture, Shinshu University, 8304 Minamiminowa-mura, Kamiina-gun, Nagano 399-4598, Japan

E-mail:mizushina@shinshu-u.ac.jp

Abbreviations: NHEK, normal human epidermal keratinocytes; MTT,3-(4,5-dimethylthiazol-2-yl)-2,5-diphenyltetrazolium bromide; $\mathrm{CPD}$, cyclobutane pyrimidine dimers; $\mathrm{PGE}_{2}$, prostaglandin $\mathrm{E}_{2}$; pol, DNA polymerase; UV, ultraviolet; KGM, keratinocyte growth medium; dTTP, 2'-deoxythymidine-5'-triphosphate; DMSO, dimethyl sulfoxide; ELISA, enzyme-linked immunosorbent assay; NMR, nuclear magnetic resonance; NER, nucleotide excision repair; TLS, translesion DNA synthesis

Key words: rose myrtle, piceatannol, normal human epidermal keratinocytes, ultraviolet B, DNA damage, DNA polymerase, anti-inflammatory activity bromide assay. This extract and piceatannol reduced the production of UVB-induced cyclobutane pyrimidine dimers and enhanced the cellular enzyme activity of the DNA polymerases in UVB-irradiated NHEK, suggesting that UVB-stimulated DNA damage was repaired by the polymerases. In addition, the secretion of prostaglandin $E_{2}$, which is an inflammatory mediator, was decreased. These results indicated that rose myrtle fruit extract and its key constituent, piceatannol, are potential photoprotective candidates for UV-induced skin damage.

\section{Introduction}

The skin is largest organ of the human body and is responsible for protecting organisms against external physical, chemical and biological insults, including ultraviolet (UV) radiation and microorganisms. Chronic exposure of the skin to solar UV radiation is a predominant factor, which contributes to the development of various skin diseases, although a number of other environmental and genetic factors are also involved. Overexposure of the skin to UV radiation causes a number of biological conditions, including sunburn, hyperpigmentation, solar keratosis, solar elastosis, skin cancer, immunosuppression and an acute inflammatory response $(1,2)$. UVB (290-320 nm) radiation induces the apoptotic cell death of keratinocytes, which manifest within the epidermis as sunburn cells. The formation of sunburn cells in UVB-exposed skin reflects the severity of the damage to the DNA. Absorption of UV produces two predominant types of DNA damage: Formation of cis-syn cyclobutane pyrimidine dimers (CPD) and pyrimidone photoproducts. However, the repair of DNA damage in UVB-exposed skin cells prevents the accumulation of damaged cells (3). UV-induced DNA damage is also an important molecular trigger for UV-induced inflammation and various forms of skin cancer (4).

Sunscreens are typically used to prevent or ameliorate the harmful effects of UV radiation on the skin (5). However, 
sufficient protection against skin photodamage may not be afforded by sunscreen alone (6). As a consequence, non-sunscreen compounds are of interest for a large proportion of the population in preventative skin care (7). Active compounds, which exert protective mechanisms against skin damage, or which inhibit pathological processes in photodamaged skin, are currently under investigation. Several plant extracts have been reported to protect the skin against various UV-induced damage models (8) and there has been considerable interest in applying plant polyphenols to the skin to prevent UV-induced skin photodamage (9).

In the present study, $80 \%$ ethanol extracts from $>50$ plants were screened for inhibitors of UVB-induced cytotoxicity, using cultured normal human epidermal keratinocytes (NHEK). Among the plant extracts investigated, extract from the fruit of rose myrtle (Rhodomyrtus tomentosa) was identified as the most marked inhibitor of cell death. Rose myrtle, which is a shrub of the Myrtaceae family and originates from Southeast Asia, grows under different conditions and is an invasive species in areas where it was introduced as an ornamental plant. The leaves, roots, buds and fruits of this plant have long been used in traditional Vietnamese, Chinese and Malay medicine. In particular, the fruits have been used to treat diarrhea and dysentery, and to boost the immune system (10). Rose myrtle fruit has an astringent taste and exhibits a deep purple color at maturity. All these properties may, at least in part, be explained by the presence of polyphenols.

In the present study, the polyphenolic inhibitors from rose myrtle fruit were isolated, and whether the extract and its isolated compounds inhibited UVB-induced cell damage and suppressed the inflammatory mediator prostaglandin $\mathrm{E}_{2}\left(\mathrm{PGE}_{2}\right)$ was investigated in NHEK. The photoprotective potential of polyphenols from rose myrtle fruit extract was subsequently assessed.

\section{Materials and methods}

Materials. The fruits of rose myrtle were obtained from Mae Chu Co., Ltd. (Nara, Japan) and Shinwa Bussan Co., Ltd. (Osaka, Japan). The NHEK and serum-free keratinocyte growth medium (KGM; trade names, EpiLife-KG2 and HuMedia-KG2), containing insulin, hydrocortisone, gentamycin/amphotericin B and growth additives, including bovine pituitary extract and human epidermal growth factor, were purchased from Kurabo Industries, Ltd. (Osaka, Japan). A chemically synthesized DNA template, poly(dA), and a customized oligo(dT $)_{18}$ DNA primer were purchased from Sigma-Aldrich (St. Louis, MO, USA). The radioactive nucleotide, ${ }^{3} \mathrm{H}$-labeled 2 '-deoxy thymidine-5'-triphosphate (dTTP; $43 \mathrm{Ci} / \mathrm{mmol}$ ) was obtained from Moravek Biochemicals, Inc. (Brea, CA, USA). All other reagents were of analytical grade and were purchased from Nacalai Tesque, Inc. (Kyoto, Japan).

Cell culture. The NHEK were seeded at a density of $3 \times 10^{5}$ cells $/ \mathrm{cm}^{2}$ into $75 \mathrm{~cm}^{2}$ cell culture flasks, and were cultured in $\mathrm{KGM}$ at $37^{\circ} \mathrm{C}$ under an atmosphere of $5 \% \mathrm{CO}_{2}$. The test compounds were dissolved in dimethyl sulfoxide (DMSO) and were diluted with medium to the appropriate concentrations, prior to adjusting the final volume to $0.05 \%$ (v/v) DMSO.
Measurement of cell viability. The NHEK were grown to subconfluence in KGM in 48 -well plates $\left(2 \times 10^{4}\right.$ cells $\left./ 0.2 \mathrm{ml}\right)$. The cultures were washed with Hank's buffer, irradiated with UVB $\left(50 \mathrm{~mJ} / \mathrm{cm}^{2}\right)$, and were subsequently treated with the test compound for $24 \mathrm{~h}$ in KGM. Following treatment, the cell viability was determined using a 3-(4,5-dimethylthiazol-2-yl)-2,5-diphenyltetrazolium bromide (MTT) assay, according to the manufacturer's instructions (11). Absorbance was measured at $\lambda 570 \mathrm{~nm}$ using the $\mu$ Quant plate reader (BioTek Instruments, Inc. Winooski, Vermont, USA), and simultaneously, the absorbance at $\lambda 650 \mathrm{~nm}$ was measured as turbidity. The difference between these measurements was regarded as the amount of blue formazan produced.

Measurement of CPD production. The NHEK were grown to subconfluence using $\mathrm{KGM}$ in $60 \mathrm{~mm}^{2}$ culture dishes $\left(2 \times 10^{5}\right.$ cells $\left./ 2 \mathrm{ml}\right)$, and were treated with the test compound for $24 \mathrm{~h}$ in KGM. The cultures were subsequently washed with Hank's buffer, irradiated with UVB $\left(80 \mathrm{~mJ} / \mathrm{cm}^{2}\right)$, and were treated with the test compound for $6 \mathrm{~h}$ in KGM. The cultured cells were collected using a cell scraper following treatment, and the nuclear DNA was purified using a QIAamp Blood kit (Qiagen, Tokyo, Japan), according to the manufacturer's instructions. The CPD levels in the quantified DNA were measured by an enzyme-linked immunosorbent assay (ELISA) using a mouse anti-CPD monoclonal antibody (1:1,000; cat. no. NMDND001; Cosmo Bio Co., Ltd., Tokyo, Japan), according to the manufacturer's instructions.

Measurement of DNA polymerase (pol) activity. The NHEK were grown to subconfluence using KGM in $60 \mathrm{~mm}^{2}$ culture dishes $\left(7.5 \times 10^{5}\right.$ cells $\left./ 5 \mathrm{ml}\right)$, and treated with the test compound for $24 \mathrm{~h}$. The cultures were subsequently washed with Hank's buffer, irradiated with UVB $\left(100 \mathrm{~mJ} / \mathrm{cm}^{2}\right)$ and cultured for $8 \mathrm{~h}$ in KGM. Following treatment, the cultured cells were collected using a cell scraper and were sonicated for $10 \mathrm{sec}$ in lysis buffer, containing $50 \mathrm{mM}$ Tris- $\mathrm{HCl}$ (pH 7.5), 1 mM EDTA, 5 mM 2-mercaptoethanol, $15 \%$ glycerol and cOmplete mini-protease protease inhibitor cocktail (Roche Diagnostics, Mannheim, Germany), using a sonicator (model, UR-20P; TOMY SEIKO CO., LTD., Tokyo, Japan; sonication level, low). The cell-extract in vitro pol activity was quantified and analyzed, as described previously $(12,13)$, with minor modifications.

For pol reactions, poly $(\mathrm{dA}) / \mathrm{oligo}(\mathrm{dT})_{18}$ and $\left[{ }^{3} \mathrm{H}\right]-\mathrm{dTTP}$ were used as the DNA template-primer substrate and nucleotide (2'-deoxynucleotide-5'-triphosphate) substrate, respectively. The standard reaction mixture for all pol species contained $50 \mathrm{mM}$ Tris- $\mathrm{HCl}(\mathrm{pH} 7.5), 1 \mathrm{mM}$ dithiothreitol, $1 \mathrm{mM} \mathrm{MgCl}_{2}, 5 \mu \mathrm{M}$ poly(dA)/oligo(dT) (A/T, $4: 1), 10 \mu \mathrm{M}\left[{ }^{3} \mathrm{H}\right]-\mathrm{dTTP}(100 \mathrm{cpm} / \mathrm{pmol}), 15 \%$ (v/v) glycerol and the prepared cell extract. The standard reaction mixture for the DNA-repair-associated pol species was identical, with the exception that it also contained $120 \mathrm{mM} \mathrm{KCl}$. Following incubation at $37^{\circ} \mathrm{C}$ for $60 \mathrm{~min}$, the radioactive DNA product was collected on a DEAE-cellulose paper disc (DE81), as previously described (14), and the radioactivity was measured in a scintillation counter (2300TR TriCarb; PerkinElmer, Downers Grove, IL, USA). 


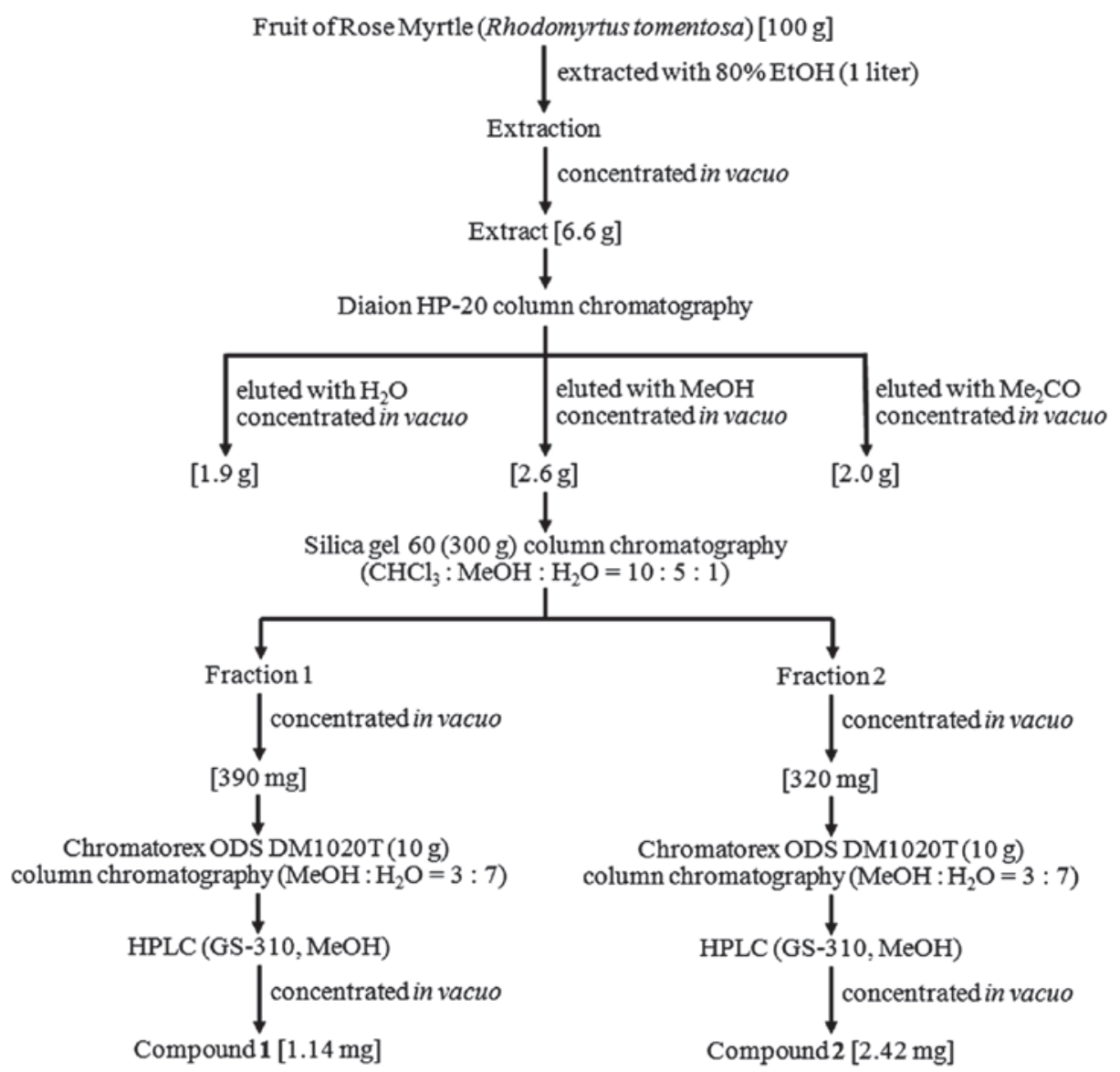

Figure 1. Method used for the purification of the compounds 1 and 2 from rose myrtle fruit. Compounds 1 (piceatannol) and 2 (piceatannol-4'-O- $\beta$-D-glucop yranoside), which exhibited increasing cell viability against UVB-exposed NHEK. EtOH, ethanol; HLPC, high-performance liquid chromatography; MeOH, methanol; NEHK, normal human epidermal keratinocytes.

Measurement of $\mathrm{PGE}_{2}$ production. The NHEK were grown to subconfluence using KGM in 48-well plates $\left(2.5 \times 10^{4}\right.$ cells $\left./ 0.2 \mathrm{ml}\right)$. The cells were cultured in KGM without hydrocortisone for 1 day, irradiated in Hank's buffer with UVB $\left(50 \mathrm{~mJ} / \mathrm{cm}^{2}\right)$, and treated with the test compound for $24 \mathrm{~h}$ in KGM without hydrocortisone. Following treatment, the culture medium was collected. The level of $\mathrm{PGE}_{2}$ in the medium was analyzed using $\mathrm{PGE}_{2}$ EIA kits (Cayman Chemical Co., Ann Arbor, MI, USA), according to the manufacturer's instructions. This assay is based on the competition between $\mathrm{PGE}_{2}$ and a $\mathrm{PGE}_{2}$-acetylcholinesterase conjugate $\left(\mathrm{PGE}_{2}\right.$ Tracer) for a limited amount of $\mathrm{PGE}_{2}$ monoclonal antibody.

Statistical analysis. All data are expressed as the mean \pm standard error of the mean for at least three independent determinations for each experiment. The statistical significance between each experimental group was analyzed using Student's t-test. $\mathrm{P}<0.05$ was considered to indicate a statistically significant difference.

\section{Results}

Isolation of cell death inhibitors against UVB-irradiated NHEK from rose myrtle fruit. Screening of UVB-damaged NHEK cytotoxic inhibitors extracted from $>50$ plants,
A

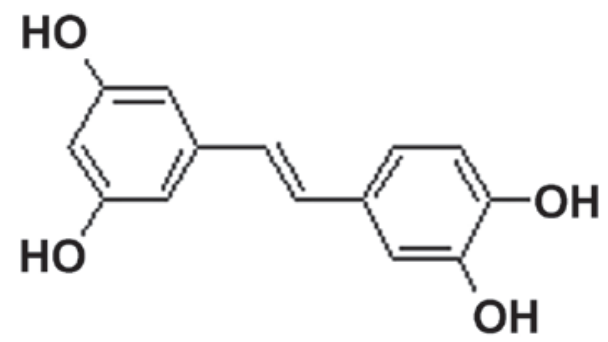

B

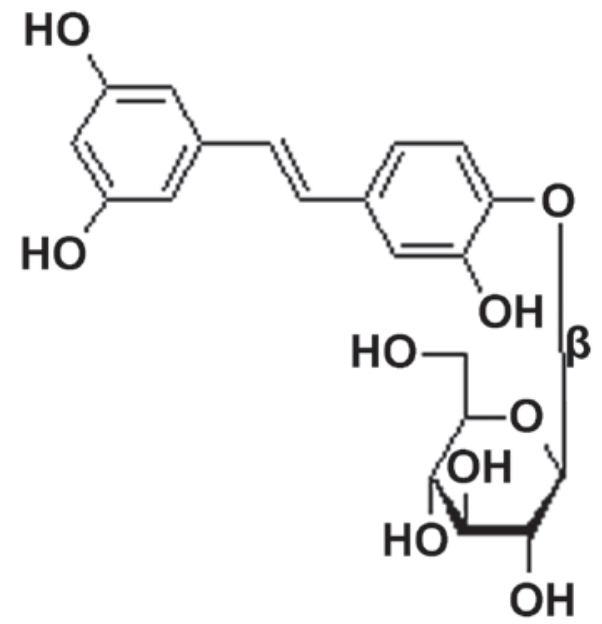

Figure 2. Structures of compounds 1 and 2 from rose myrtle fruit. (A) Piceatannol (compound 1) and (B) piceatannol-4'-O- $\beta$-D-glucopyrano side (compound 2). 


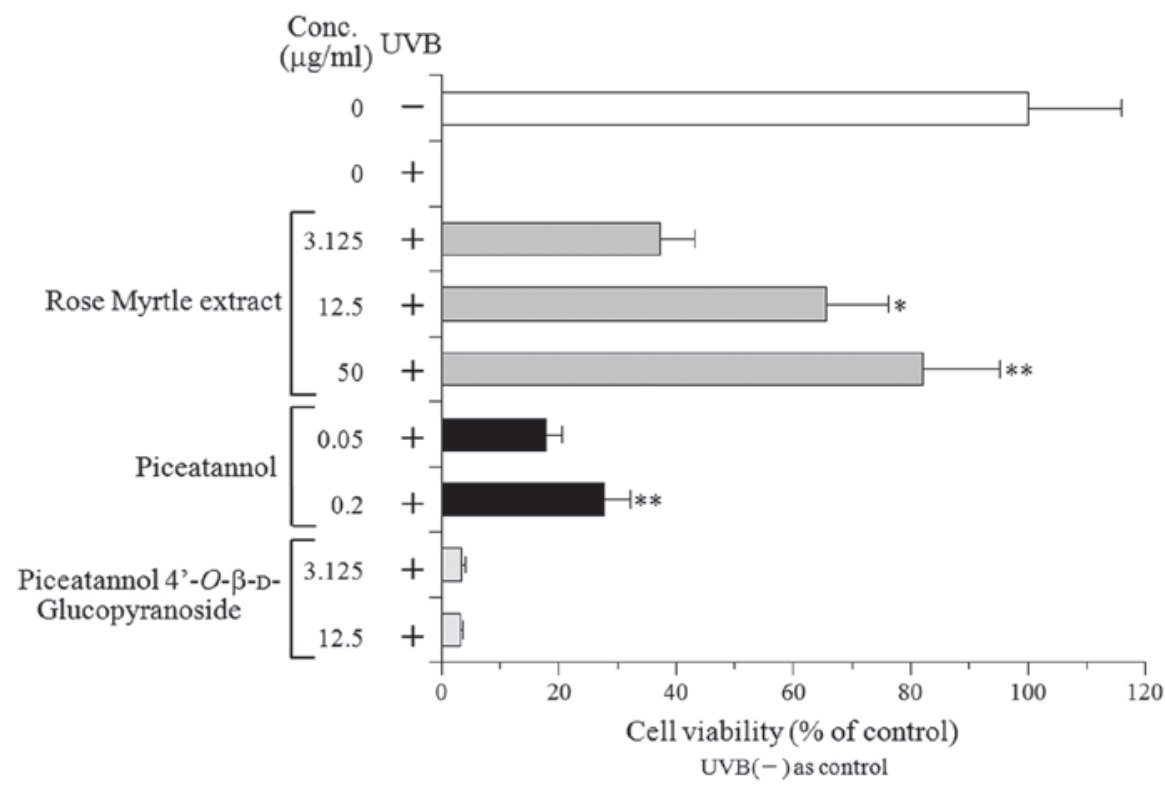

Figure 3. Effect of rose myrtle extract, piceatannol and piceatannol-4'-O- $\beta$-D-glucopyranoside on cell viability following the exposure of NHEK to UVB radiation. The NHEK were irradiated with UVB $\left(50 \mathrm{~mJ} / \mathrm{cm}^{2}\right)$ and treated with each compound at the indicated concentrations. A 3-(4,5-dimethylthiazol-2-yl)-2,5-diphenyltetrazolium bromide assay was used to assess the number of living cells $24 \mathrm{~h}$ following treatment. The cell viability of the vehicle control with or without UVB irradiation was considered to be 0 or $100 \%$, respectively. All data are expressed as the mean \pm standard error of the mean ( $\mathrm{n}=6$; ${ }^{*} \mathrm{P}<0.05$ and ${ }^{* *} \mathrm{P}<0.01$, compared with the UVB (+) vehicle control). Conc, concentration; UVB, ultraviolet B; NHEK, normal human epidermal keratinocytes.

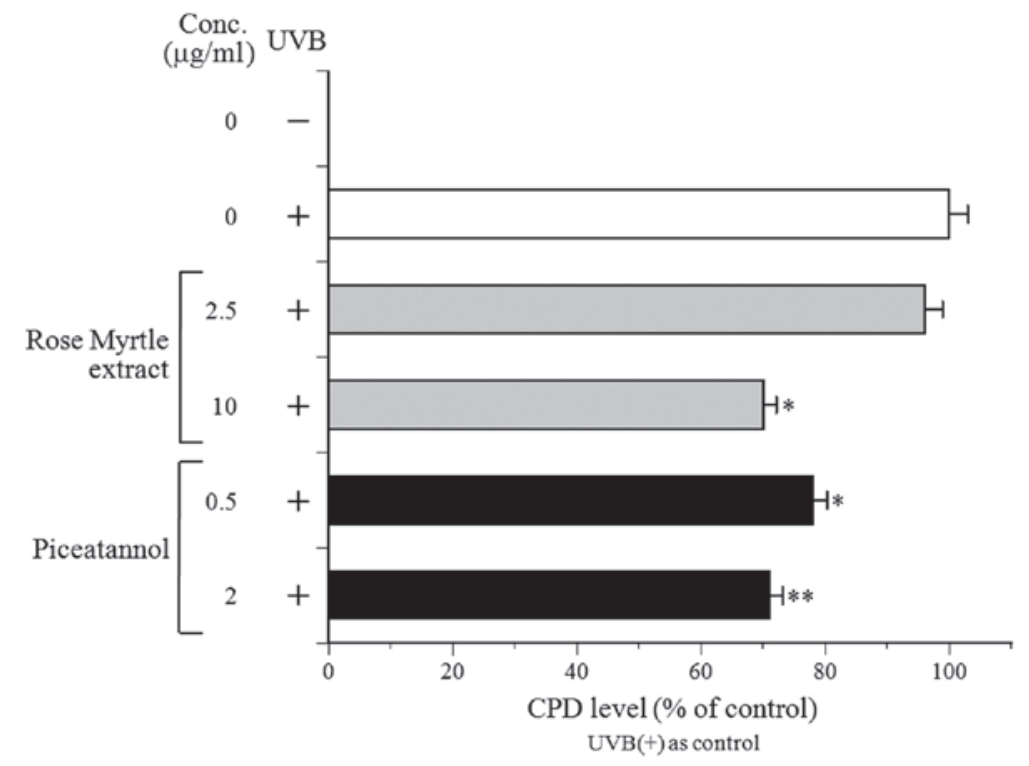

Figure 4. Effect of rose myrtle extract and piceatannol on UVB-induced CPD production in NHEK. The NHEK were incubated with each compound at the indicated concentrations prior to and following UVB $\left(80 \mathrm{~mJ} / \mathrm{cm}^{2}\right)$ irradiation. CPD was quantitatively determined by DNA-enzyme-linked immunoassay. The production of CPD by the vehicle control with or without UVB irradiation was considered to be 0 or $100 \%$, respectively. All data are expressed as the mean \pm standard error of the mean ( $\mathrm{n}=6$; ${ }^{*} \mathrm{P}<0.05$ and ${ }^{* *} \mathrm{P}<0.01$, compared with the UVB (+) vehicle control). Conc, concentration; $\mathrm{CPD}$, cyclobutane pyrimidine dimers; NHEK, normal human epidermal keratinocytes.

using $80 \%$ ethanol, demonstrated that the extract from the fruit of rose myrtle exhibited the most marked protective activity on UVB-induced cytotoxicity. For further experiments, $100 \mathrm{~g}$ rose myrtle fruit was extracted with 1 litre $80 \%$ ethanol. The evaporated extract (6.6 g) was dissolved in distilled water and subjected to hydrophobic column chromatography (Diaion HP-20; Sigma-Aldrich; Fig. 1). A total of three hydrophobic chromatography fractions were collected: Water, methanol and acetone. The methanol fraction was evaporated
(2.6 g) and subjected to silica gel 60 column chromatography, and subsequently eluted with chloroform:methanol:water (v:v:v, 10:5:1). A total of two active fractions were obtained and independently purified by reverse-phase silica gel column chromatography (Chromatorex ODS DM1020T; Fuji Silysia Chemical, Ltd., Durham, NC, USA) and continuous high-performance liquid chromatography. This process resulted in two white, powdery compounds, 1 and 2 (1.14 and $2.42 \mathrm{mg}$, respectively; Fig. 1). 

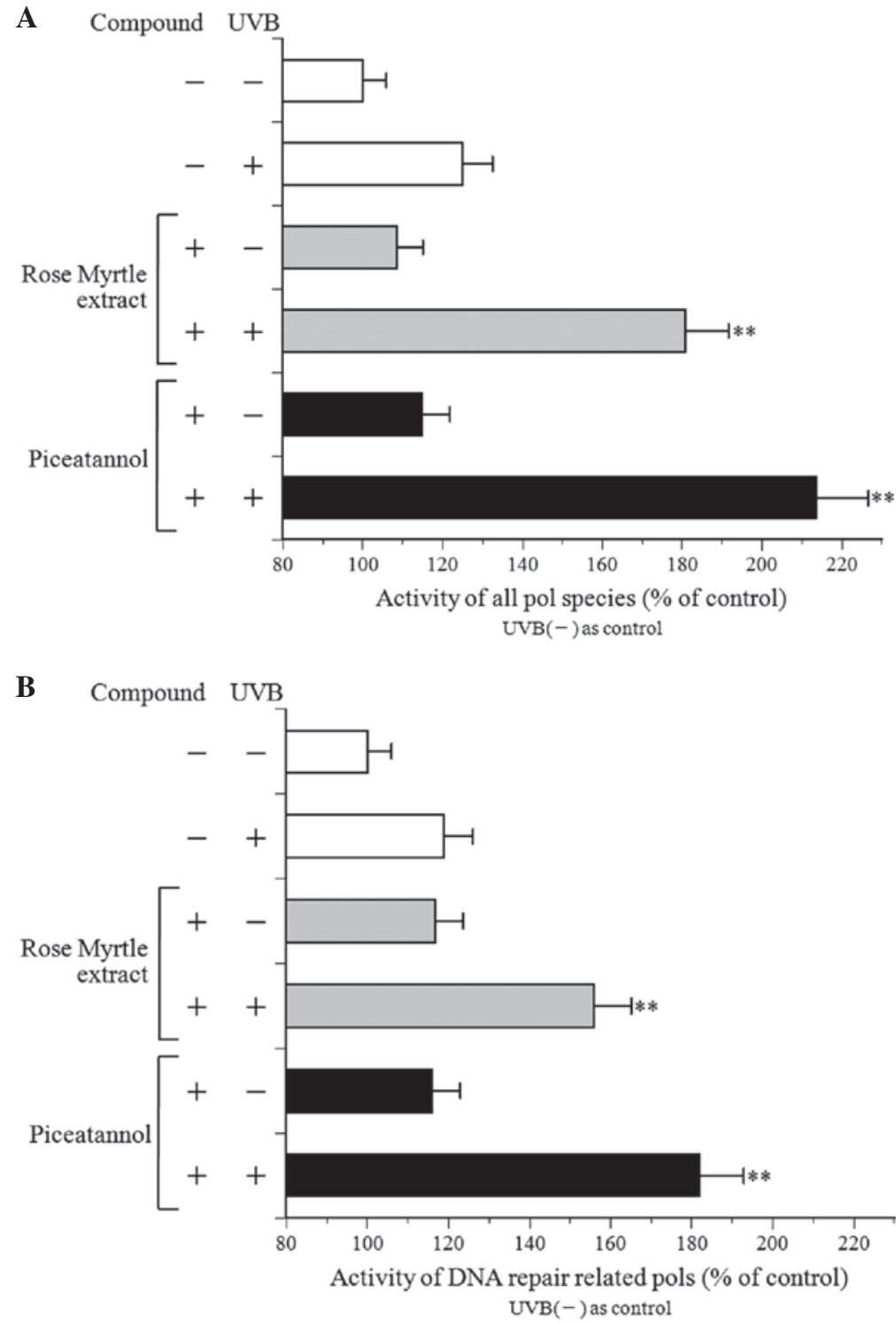

Figure 5. Effect of rose myrtle extract and piceatannol on the activity of cellular pols in NHEK with or without UVB irradiation. (A) The pol activity of all pol species was determined using standard reaction conditions without $\mathrm{KCl}$. (B) The pol activity of DNA repair-associated pol species was assessed using standard reaction conditions with $120 \mathrm{mM} \mathrm{KCl}$. The NHEK were incubated with or without each compound $(10 \mu \mathrm{g} / \mathrm{ml}$ rose myrtle extract and $2 \mu \mathrm{g} / \mathrm{ml}$ piceatannol) prior to UVB $\left(100 \mathrm{~mJ} / \mathrm{cm}^{2}\right)$ irradiation. The pol activity of the vehicle control without UVB irradiation was considered to be $100 \%$. All data are expressed as the mean \pm standard error of the mean $\left(n=3 ;{ }^{* *} \mathrm{P}<0.01\right.$ compared with the UVB (-) vehicle control). Pol, polymerase; NHEK, normal human epidermal keratinocytes; UVB, ultraviolet B.

Compounds 1 and 2 were identified as a polyphenol, piceatannol, and its glucoside, piceatannol-4'-O- $\beta$-D-glucop yranoside, respectively, from the high-resolution mass spectrometric data and the ${ }^{1} \mathrm{H}$ and ${ }^{13} \mathrm{C}$ nuclear magnetic resonance (NMR) spectral data (their structures are demonstrated in Fig. 2). These spectroscopic data were consistent with a previous report (15). Subsequently, the rose myrtle fruit extract and these two compounds, purified to $>98 \%$ as determined by NMR analysis (data not shown), were used for further investigation.

Effect of the rose myrtle fruit extract, piceatannol and pice atannol-4'-O- $\beta$-D-glucopyranoside on cell viability in UVB-exposed NHEK. The treatment of cultured NHEK with rose myrtle fruit extract and its two isolated compounds at concentrations up to 100 and $20 \mu \mathrm{g} / \mathrm{ml}$, respectively, failed to induce any cytotoxic effects (the cell viability was $>95 \%$ following $24 \mathrm{~h}$ treatment; data not shown). Subsequently, the following experiments were performed up to the concentration limits mentioned above.

The NHEK were treated following UVB irradiation at a dose of $50 \mathrm{~mJ} / \mathrm{cm}^{2}$. The cell viability was analyzed $24 \mathrm{~h}$ post-irradiation and was compared with non-treated cells. The extract markedly inhibited UVB-induced NHEK cytotoxicity in a dose-dependent manner. The cell viability determined using a concentration of $50 \mathrm{mg} / \mathrm{ml}$ extract was improved by $>80 \%$ compared with the non-treated cells. Of the two rose myrtle fruit extract components, piceatannol increased the cell viability of the UVB-exposed NHEK in a dose-dependent manner; however, piceatannol-4'-O- $\beta$-D-glucopyranoside demonstrated no protective effect. These results suggested that piceatannol, which is the aglycone of piceatannol-4'-O- $\beta-\mathrm{D}$ - 

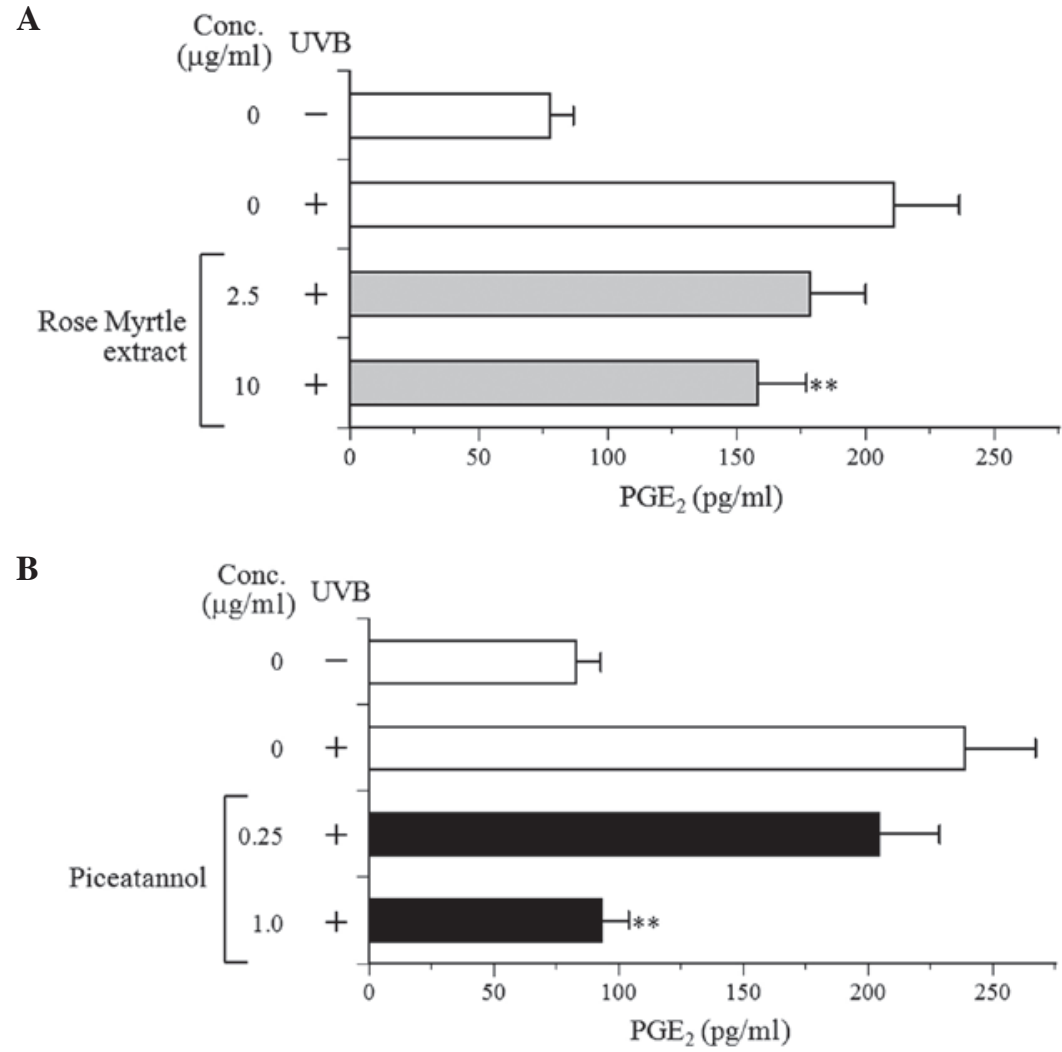

Figure 6. Effect of rose myrtle extract and piceatannol on the UVB-induced $\mathrm{PGE}_{2}$ production in NHEK. The NHEK were incubated with (A) rose myrtle extract and (B) piceatannol at the indicated concentrations, following UVB $\left(50 \mathrm{~mJ} / \mathrm{cm}^{2}\right)$ irradiation. The supernatant level of $\mathrm{PGE}_{2}$ was quantitatively determined using an enzyme-linked immunoassay. All data are expressed as the mean \pm standard error of the mean $\left(\mathrm{n}=5 ;{ }^{* *} \mathrm{P}<0.01\right.$, compared with the $\mathrm{UVB}(+)$ vehicle control). $\mathrm{PGE}_{2}$, prostaglandin $\mathrm{E}_{2}$; NHEK, normal human epidermal keratinocytes; UVB, ultraviolet $\mathrm{B}$.

glucopyranoside, is the protective component of rose myrtle extract, and that the aglycone structure is important for this protective activity.

Since rose myrtle fruit extract and piceatannol protected against UVB-induced cell death, the subsequent experiments focused on these two compounds.

Effect of rose myrtle fruit extract and piceatannol on CPD production in $U V B$-exposed NHEK. CPD formation is one of the most important characteristics of DNA damage and mutagenesis (16). The subsequent experiments, therefore, investigated whether rose myrtle extract and its polyphenolic component, piceatannol, may influence the removal of CPD from DNA in UVB-irradiated NHEK. Exposure of NHEK to $80 \mathrm{~mJ} / \mathrm{cm}^{2}$ UVB induced CPD formation, as measured immediately following irradiation, and served as a reference for DNA damage (Fig. 4). To assess DNA repair in the irradiated cultures, CPD levels were determined following UVB exposure and compared with the non-repaired control cells. Both rose myrtle extract and piceatannol decreased CPD production in UVB-exposed NHEK in a dose-dependent manner, with $10 \mu \mathrm{g} / \mathrm{ml}$ extract and 0.5 and $2 \mu \mathrm{g} / \mathrm{ml}$ piceatannol exhibiting a $20 \%$ reduction in CPD compared with the non-treated control cells. These results suggested that rose myrtle extract and/or piceatannol may stimulate DNA repair activity against UVB-damaged DNA in NHEK. Consequently, the present study investigated NHEK cellular pol activity with or without UVB irradiation.
Effect of rose myrtle fruit extract and piceatannol on pol activity in UVB-exposed NHEK. Eukaryotic cells are reported to contain 15 pol species, which belong to four families: Family A (pols $\gamma, \theta$, and $v$ ), family B (pols $\alpha, \delta, \varepsilon$, and $\zeta$ ), family $\mathrm{X}$ [pols $\beta, \lambda, \mu$ and terminal deoxynucleotidyl transferase (TdT)] and family Y (pols $\eta, \iota, \kappa$ and REV1) $(17,18)$. All pol species are active in buffer with salts, including $\mathrm{NaCl}$ and $\mathrm{KCl}$, however B-family pols are inhibited by salt (19). Therefore, a standard reaction mixture with or without $120 \mathrm{mM} \mathrm{KCl}$ was used to detect the activity of all pol species (Fig. 5A) or DNA repair-associated pol species (Fig. 5B). The activity of the DNA repair-associated pol species, including the X-and Y-family of pols, was enhanced by salt $(120 \mathrm{mM} \mathrm{KCl})$ addition (19). The activities of the purified calf pol $\alpha$ and rat pol $\beta$, which are B-and $\mathrm{X}$-family pols, respectively, with $120 \mathrm{mM} \mathrm{KCl}$ were 1.5 -fold higher and 0.1-fold lower, respectively, compared with those without $\mathrm{KCl}$ (data not shown). The cellular pol activity of the standard reaction mixture without salt in NHEK was higher compared with that of the standard reaction mixture with salt (Fig. 5).

NHEK pol activity with or without UVB irradiation and treatment with the test compound was similar (Fig. 5). In non-treated compounds, UVB exposure at $100 \mathrm{~mJ} / \mathrm{cm}^{2}$ increased pol enzyme activity by $\sim 1.2$-fold. In the non-UVB-irradiated NHEK, the extract and piceatannol marginally increased the NHEK pol activity. In addition, the pol activities were increased markedly in the UVB-exposed NHEK. These results indicated a synergistic effect of UVB irradiation and rose myrtle extract 
and/or piceatannol on the induction of pol enzyme activity, particularly DNA repair-associated pols, suggesting that activation of these enzymes reduces CPD production.

Effect of rose myrtle fruit extract and piceatannol on $P G E_{2}$ production in UVB-exposed NHEK. The potential effects of the extract and piceatannol on $\mathrm{PGE}_{2}$ production were subsequently investigated to determine whether they were associated with the anti-inflammatory properties in NHEK. UVB irradiation increased $\mathrm{PGE}_{2}$ secretion by $\sim 2.9$-fold in non-irradiated NHEK to $238.6 \mathrm{pg} / \mathrm{ml} \mathrm{PGE}$ (Fig. 6). The extract and piceatannol demonstrated a decreased production of $\mathrm{PGE}_{2}$ in a dose-dependent manner, suggesting that rose myrtle extract and/or piceatannol suppressed the inflammation stimulated by UVB in NHEK.

\section{Discussion}

In the present study, the protective effects of $80 \%$ ethanol extracts from the fruit of rose myrtle and its component, piceatannol (Fig. 2A), against UVB-induced cytotoxicity in cultured NHEK were investigated. It is known that $\sim 90 \%$ of skin inflammation cases are attributed to solar UV radiation, particularly its UVB component, which is absorbed efficiently by cellular DNA (20). UVB radiation penetrates the skin epidermis, inducing direct and indirect DNA-damaging effects. Rose myrtle extract and piceatannol increased cell viability in the UVB-exposed NHEK (Fig. 3), and promoted the removal of CPD photoproducts (Fig. 4), suggesting an improvement in DNA damage repair. The formation of CPD and 6-4 pyrimidine-pyrimidone photoproducts are the most predominant DNA lesions in skin following UVB and UVA exposure $(16,21)$. The predominant repair mechanism of UVB-induced DNA damage is nucleotide excision repair (NER). When skin cells are exposed to excessive UV radiation, the NER capacity is reduced and CPD lesions remain, which may result in cellular death, senescence, mutagenesis and carcinogenesis of the skin (21). An enhancement in DNA repair provides a plausible explanation to account for how extract and piceatannol exert a protective effect on UVB-irradiated NHEK viability in culture, and on sun-damaged cell formation in UVB-irradiated human skin explants.

The effect of rose myrtle extract and piceatannol on in vitro pol activity in UVB-irradiated cultured NHEK cell extracts was also analyzed, and the enzyme activity markedly increased (Fig. 5). DNA-dependent pol catalyzes the addition of deoxyribonucleotides to the 3'-hydroxy terminus of primed double-stranded DNA molecules (19). The human genome encodes at least 15 pols, which function in cellular DNA synthesis $(22,23)$. Eukaryotic cells contain three replicative pols $(\alpha, \delta$ and $\varepsilon$ ), one mitochondrial pol $(\gamma)$ and at least 11 non-replicative pols $(\beta, \zeta, \eta, \theta, \iota, \kappa, \lambda$, $\mu, \gamma$, TdT and REV1) $(17,18)$. Pols have a highly conserved structure, with their overall catalytic subunits exhibiting little variation among species. Conserved enzyme structures, which are preserved over time, normally perform important cellular functions, which confer evolutionary advantages. Based on sequence homology, eukaryotic pols are divided into four predominant families: A, B, X and Y (17). Family
A includes mitochondrial pol $\gamma$ and pols $\theta$ and $v$; family $B$ includes the three replicative pols, $\alpha, \delta$ and $\varepsilon$, and pol $\zeta$; family $\mathrm{X}$ comprises pols $\beta, \lambda, \mu$ and TdT; family $\mathrm{Y}$ includes pols $\eta, \iota, \kappa$ and REV1 (18). At least seven pols, comprising two of the A-family pols (pols $\theta$ and $v$ ), one B-family pol (pol $\zeta$ ) and four Y-family pols (pols $\eta, \iota, \kappa$ and REV1), are capable of substantial translesion DNA synthesis (TLS) activity (18). The most notable TLS pol, which can bypass $\mathrm{UV}$ radiation-induced DNA damage, is pol $\eta$, which bypasses thymine-thymine (TT)-CPD with high efficiency and fidelity. Purified human pol $\eta$ correctly inserts A deoxynucleotides opposite to linked bases of a TT-CPD (24). Pol $\beta$, the base excision repair pol, enhances UV-induced genetic instability, and facilitates translesion replication of CPD in a UV lesion bypass (25). Consequently, the activation of the DNA repair-associated pols, $\beta$ and $\eta$, is likely to be important for maintaining UVB-induced DNA damage.

The present study demonstrated that rose myrtle extract and piceatannol decreased UVB-induced secretion of the inflammatory mediator, $\mathrm{PGE}_{2}$ (Fig. 6). NHEK-derived inflammatory mediators exert an important role in the development of the inflammatory reaction in UVB-exposed skin (26). Numerous studies have demonstrated that $\mathrm{PGE}_{2}$ mediates the signals involved in the induction of erythema, angiogenesis, vasodilatation and vascular permeability (27), and $\mathrm{PGE}_{2}$ signaling pathways promote photoaging and the development of UVB-induced skin carcinogenesis (28). Taken together, the present data on the inhibitory effects of rose myrtle extract and piceatannol against UVB-induced $\mathrm{PGE}_{2}$ expression in NHEK demonstrated the anti-inflammatory properties of these compounds. These results supported the hypothesis that these compounds have anti-inflammatory capability, not only against UVB-induced inflammation, but also against inflammatory reactions caused by other irritants. Since rose myrtle extract and piceatannol do not absorb $\mathrm{UVB}$, the data in the present study suggested that they act in a non-sunscreen manner to protect against UVB-induced inflammatory induction.

On analysis of $>50$ plants, rose myrtle fruit extracts were identified as being the most effective at increasing cell viability in UVB-irradiated NHEK. Rose myrtle fruit extract and its isolated polyphenolic component, piceatannol, decreased the production of CPD and $\mathrm{PGE}_{2}$, which are a DNA damage photoproduct and an inflammatory mediator, respectively. These results suggested that rose myrtle piceatannol protects the skin from UVB-induced damage via the enhancement of DNA repair-associated pol enzyme activity, and suppressed inflammation. Consequently, the extract and/or piceatannol may be beneficial in the photoprotection of skin; however, further studies are required to elucidate the mechanism by which piceatannol confers this protective activity.

\section{Acknowledgements}

This study was supported, in part, by the Ministry of Education, Culture, Sports, Science and Technology, Japan (MEXT)-Supported Program for the Strategic Research Foundation at Private Universities, 2012-2016. Dr Yoshiyuki Mizushina received a Grants-in-Aids for the 25th (2014) Cosmetology Research Foundation (Japan). 


\section{References}

1. Berneburg M, Plettenberg $\mathrm{H}$ and Krutmann J: Photoaging of human skin. Photodermatol Photoimmunol Photomed 16 : 239-244, 2000.

2. Verschooten L, Claerhout S, Van Laethem A, Agostinis P and Garmyn M: New strategies of photoprotection. Photochem Photobiol 82: 1016-1023, 2006.

3. Moriwaki S and Takahashi Y: Photoaging and DNA repair. J Dermatol Sci 50: 169-176, 2008.

4. Kripke ML, Cox PA, Alas LG and Yarosh DB: Pyrimidine dimers in DNA initiate systemic immunosuppression in UV-irradiated mice. Proc Natl Acad Sci USA 89: 7516-7520, 1992.

5. Autier P: Sunscreen abuse for intentional sun exposure. Br J Dermatol 161 (Suppl 3): 40-45, 2009.

6. Schroeder P and Krutmann J: What is needed for a sunscreen to provide complete protection. Skin Therapy Lett 15: 4-5, 2010.

7. Matsui MS, Hsia A, Miller JD, Hanneman K, Scull H, Cooper KD and Baron E: Non-sunscreen photoprotection: Antioxidants add value to a sunscreen. J Investig Dermatol Symp Proc 14: 56-59, 2009.

8. Yaar M and Gilchrest BA: Photoageing: Mechanism, prevention and therapy. Br J Dermatol 157: 874-887, 2007.

9. Nichols JA and Katiyar SK: Skin photoprotection by natural polyphenols: Anti-inflammatory, antioxidant and DNA repair mechanisms. Arch Dermatol Res 302: 71-83, 2010.

10. Do TL: SIM. In: Medicine plants and remedies of Vietnam. 16th edition. Thoi Dai Publication House, Hanoi, Vietnam, pp434-435, 2011.

11. Mosmann T: Rapid colorimetric assay for cellular growth and survival: Application to proliferation and cytotoxicity assays. J Immunol Methods 65: 55-63, 1983.

12. Mizushina Y, Yagi H, Tanaka N, Kurosawa T, Seto H, Katsumi K, Onoue M, Ishida H, Iseki A, Nara T, et al: Screening of inhibitor of eukaryotic DNA polymerases produced by microorganisms. J Antibiot (Tokyo) 49: 491-492, 1996.

13. Mizushina Y, Yoshida S, Matsukage A and Sakaguchi K: The inhibitory action of fatty acids on DNA polymerase $\beta$. Biochim Biophys Acta 1336: 509-521, 1997.

14. Lindell TJ, Weinberg F, Morris PW, Roeder RG and Rutter WJ: Specific inhibition of nuclear RNA polymerase II by $\alpha$-amanitin. Science 170: 447-449, 1970.
15. Kashiwada Y, Nonaka G, Nishioka I, Nishizawa M and Yamagishi T: Studies on rhubarb (Rhei rhizoma). XIV. Stilbene glucosides. Chem Pharm Bull 36: 1545-1549, 1988.

16. Marrot L and Meunier JR: Skin DNA photodamage and its biological consequences. J Am Acad Dermatol (Suppl 2) 58: S139-S148, 2008.

17. Loeb LA and Monnat RJ Jr: DNA polymerases and human disease. Nat Rev Genet 9: 594-604, 2008.

18. Lange SS, Takata K and Wood RD: DNA polymerases and cancer. Nat Rev Cancer 11: 96-110, 2011.

19. Kornberg A and Baker TA: Eukaryotic DNA replication. DNA replication 2 nd edition. In Freeman, W. D. and Co. (Ed.), University Science Books, California, Chapter 6: pp197-225, 1990.

20. Gailani MR, Leffell DJ, Ziegler A, Gross EG, Brash DE and Bale AE: Relationship between sunlight exposure and a key genetic alteration in basal cell carcinoma. J Natl Cancer Inst 88: 349-354, 1996

21. Pagès V and Fuchs RP: How DNA lesions are turned into mutations within cells? Oncogene 21: 8957-8966, 2002.

22. Bebenek K and Kunkel TA: DNA Repair and Replication. In: Advances in Protein Chemistry. Yang W (ed.). Elsevier, San Diego, CA, pp137-165, 2004.

23. Hübscher U, Maga G and Spadari S: Eukaryotic DNA polymerases. Annu Rev Biochem 71: 133-163, 2002.

24. Johnson RE, Washington MT, Prakash S and Prakash L: Fidelity of human DNA polymerase eta. J Biol Chem 275: 7447-7450, 2000.

25. Servant L, Cazaux C, Bieth A, Iwai S, Hanaoka F and Hoffmann JS: A role for DNA polymerase $\beta$ in mutagenic UV lesion bypass. J Biol Chem 277: 50046-50053, 2002.

26. Kabashima K, Nagamachi M, Honda T, Nishigori C, Miyachi Y, Tokura $Y$ and Narumiya $S$ : Prostaglandin $E_{2}$ is required for ultraviolet $\mathrm{B}$-induced skin inflammation via $\mathrm{EP} 2$ and $\mathrm{EP} 4$ receptors. Lab Invest 87: 49-55, 2007.

27. Trompezinski S, Pernet I, Schmitt D and Viac J: UV radiation and prostaglandin $\mathrm{E}_{2}$ up-regulate vascular endothelial growth factor (VEGF) in cultured human fibroblasts. Inflamm Res 50: 422-427, 2001

28. Rundhaug JE, Mikulec C, Pavone A and Fischer SM: A role for cyclooxygenase-2 in ultraviolet light-induced skin carcinogenesis. Mol Carcinog 46: 692-698, 2007. 